\title{
Pregnancy outcomes in younger and older adolescent mothers with severe preeclampsia
}

Priscila E Parra-Pingel ${ }^{1,2}$

Luis A Quisiguiña-Avellán ${ }^{1,2}$

Luis Hidalgo ${ }^{1,2}$

Peter Chedraui ${ }^{1,2}$

Faustino R Pérez-López

'High Risk Pregnancy Labor and Delivery Unit, Enrique C. Sotomayor Obstetrics and Gynecology Hospital Guayaquil, ${ }^{2}$ Institute of Biomedicine, Research Area for Women's Health, Facultad de Ciencias Médicas, Universidad Católica de Santiago de Guayaquil, Guayaquil, Ecuador; ${ }^{3}$ Department of Obstetrics and Gynecology, Hospital Universitario Lozano Blesa, Facultad de Medicina Universidad de Zaragoza, Zaragoza, Spain
Correspondence: Faustino R Pérez-López Department of Obstetrics and Gynecology, University of Zaragoza and Lozano Blesa University Hospital, Domingo Miral s, /n Zaragoza 50009, Spain

$\mathrm{Tel}+3497676 \quad 734$

Fax +34 $97676 \quad 1735$

Email faustino.perez@unizar.es
This article was published in the following Dove Press journal:

Adolescent Health, Medicine and Therapeutics

6 June 2017

Number of times this article has been viewed

Background: Adolescent mothers are at higher risk for preeclampsia, but the effect of their age on the outcome of the pregnancy complication is not clear.

Objective: To describe maternal and neonatal outcomes among singleton adolescent pregnancies complicated with severe preeclampsia in a low-income-setting hospital and compare results according to age.

Materials and methods: Maternal and neonatal outcomes of 213 adolescent mothers complicated with severe preeclampsia delivering at the Enrique C. Sotomayor Obstetrics and Gynecology Hospital (Guayaquil, Ecuador) were analyzed and compared according to their age ( 16 or less years, $n=82$ vs $17-19$ years, $n=131$ ).

Results: Cesarean section rate was high in both studied groups; otherwise, obstetrical outcome did not differ and there were no maternal deaths or severe complications. Neonatal outcome was adverse in the two groups evidenced by high rates of preterm birth, small-for-gestationalage and low-birth-weight infants, low first-minute Apgar scores and admissions to neonatal intensive care; however, it was not significantly different between the analyzed groups. There were no neonatal deaths among mothers aged 16 or less and 4 in the group aged 17-19 years. This was, however, not significant ( $p=0.30)$.

Conclusion: Pregnancy outcome in this adolescent population with severe preeclampsia was similarly adverse, independent of maternal age.

Keywords: preeclampsia, adolescents, Ecuador, neonatal, maternal, outcome

\section{Background}

Pregnancy during adolescence is a significant burden as compared to adults because of physical immaturity and overlapping maternal growth, nutritional status, socioeconomic factors, partner abuse and emotional overload. ${ }^{1-4}$ The prevalence of preeclampsia may be twice as higher in adolescents. ${ }^{5,6}$ In younger women, preeclampsia and eclampsia increase the risk of adverse maternal (i.e., severe complications, morbidity, maternal near-miss cases and cesarean deliveries) ${ }^{7}$ and perinatal outcomes (i.e., preterm birth, intrauterine growth restriction [IUGR], low birth weight and admissions to intensive care units)..$^{8,9}$ These negative outcomes may be influenced by adequacy of prenatal care, ethnicity, and sociodemographic and family factors. ${ }^{9-11}$ Previously we reported that younger pregnant adolescents have worse neonatal outcomes when compared with older teens. ${ }^{12}$ Bearing these issues in mind, the aim of the current study was to describe pregnancy outcome (maternal and neonatal) in singleton adolescent pregnancies complicated with severe preeclampsia in a low-income-setting Ecuadorian hospital and compare results in accordance to their age. 
In developed countries, screening of preeclampsia has improved through the combination of adequate prenatal care, evaluation of sociodemographic characteristics and early biophysical and biochemical screening (i.e., uterine artery Doppler or biochemical assessment). This combination has aided at designing preventive interventions (i.e., early induction of labor under optimal conditions). ${ }^{13,14}$ In developing countries, inadequate prenatal care and management of obstetric pathology, including preeclampsia, may be delayed, therefore increasing adverse outcomes. ${ }^{15,16}$

\section{Materials and methods Study design and participants}

This was a retrospective and comparative study that analyzed data of adolescents delivering at the High Risk Pregnancy Labour and Delivery Unit of the Enrique C. Sotomayor Obstetrics and Gynecology Hospital from January 1, 2013, to December 31, 2013. Inclusion criteria were maternal age 19 or less, with singleton pregnancies $>20$ weeks gestations complicated with severe preeclampsia. Sotomayor Hospital is one of four health care facilities managed by the Junta de Beneficencia de Guayaquil, a private nonprofit organization that provides partially subsidized health care and education to the low-income population of Guayaquil and its surroundings. ${ }^{17}$ Low income was defined as a total monthly family income of less than USD $600 .{ }^{18}$ Severe preeclampsia cases were defined according to criteria of the American College of Obstetricians and Gynecologists: blood pressure $\geq 160$ (systolic) or $110 \mathrm{mmHg}$ (diastolic), evidence of fetal (oligohydramnios, growth restriction) or maternal end-organ compromise (acute renal failure, acute pulmonary edema, and so on). ${ }^{19}$ Women with multiple gestations, mild preeclampsia, eclampsia, HELLP syndrome or gestational hypertension without proteinuria were excluded for analysis. Maternal and neonatal data were retrieved from medical records and registered in a data sheet created for the purpose of the present study. The research protocol was reviewed and approved by the Scientific Research Committee of the Enrique C. Sotomayor Obstetrics \& Gynecology Hospital. Due to the retrospective design of the study, the committee approved the review of patient's medical records without their consent. Confidentiality was maintained for all patient data.

\section{Outcome measures}

\section{Maternal data}

Maternal data included age (years), parity (primigravid or not), place of residency (rural or not), marital status (cohabiting with partner or not), systolic and diastolic blood pressure (mmHg) upon admission, noxious habits during pregnancy (illicit drug, tobacco or alcohol use, yes/ no), route of delivery (cesarean section or vaginal delivery), antenatal admission (yes/no), obstetrical outcome indices (i.e., intrapartum meconium, oligohydramnios, premature rupture of membranes, and so on), prepartum and postpartum blood parameters, and the number of maternal deaths, maternal severe complications and admissions to the adult intensive care unit.

\section{Neonatal data}

Neonatal data included gestational age at birth (weeks), condition of infant (live or dead), infant anthropometry (weight $[\mathrm{g}]$, length $[\mathrm{cm}]$ and head circumference $[\mathrm{cm}])$ and Apgar scores at birth (first and fifth minute). The number of neonatal deaths, complications or admissions to the neonatal intensive care unit (NICU) was also registered. Gestational age was defined as the final estimate recorded by the physician who did the first neonatal examination immediately after birth and/ or based on last menstrual period. Small-for-gestational-age (SGA) infants were defined as those having a birth weight of $<10$ th percentile for their corresponding gestational age. ${ }^{20}$ Infants having a birth weight $<10$ th percentile with clinical evidence of IUGR were defined as SGA associated with IUGR. $^{20}$

Low birth weight was defined as a weight $<2500 \mathrm{~g}^{21}$ Preterm birth was defined as that occurring at $<37$ weeks' gestation. Non-ill neonates were placed in the neonatal ward for a minimum of 24 hours and then discharged with the mother; otherwise, they were admitted to the NICU.

\section{Statistical analysis}

Statistical analysis was performed using SPSS Version 22.0 (IBM SPSS, Armonk, NY, USA) after stratification for two groups: 16 or less or 17-19 years. The Kolmogorov-Smirnov test was used to determine the normality of the distribution of continuous data. Data are presented as mean \pm standard deviation (for normally distributed data), medians/interquartile ranges (for non-normally distributed data) and frequencies/ percentages. Comparisons of maternal and neonatal continuous measures were performed with the Mann-Whitney $U$-test (nonparametric test/non-normally distributed data) or the Student's $t$-test (parametric test/normally distributed data). The chi-square test or Fisher's exact test (for cases including zero values) was used to compare percentages. All calculated $p$-values were two-sided and the significance level set at $<0.05$. 


\section{Results}

During the study period, there were 26,163 live births. Of these, a total of 4,862 were aged 19 or less $(18.7 \%)$. A $6 \%$ of all live births $(\mathrm{n}=1,575)$ were identified as having severe preeclampsia, of which $213(13.5 \%)$ were aged 19 or less years and had singleton pregnancies. Maternal demographic and obstetrical outcome data according to their age are shown in Table 1. Cesarean section rate was high in both analyzed groups, and except for a higher number of antenatal admissions in the 17-19 age group, overall obstetrical outcome did not differ and there were no maternal deaths or any other severe complications. More than $40 \%$ of cesarean sections (similar in both groups) were carried out in women with an unfavorable cervix and uncontrollable blood pressure with signs of maternal neurological compromise. Neonatal outcome was adverse in both groups evidenced by high rates of preterm birth, SGA and low-birth-weight infants, low first-minute Apgar scores and admissions to NICU; however, it was not significantly different between the studied groups (Table 2). There were no neonatal deaths among mothers aged 16 or less and four in the group aged 17-19 years. This was, however, not significant $(p=0.30)$.

\section{Discussion}

Pregnancy during adolescence is a significant social problem. Indeed, nearly a fifth of women delivering at Sotomayor Hospital are teens. Adolescents, especially younger ones, are more likely to have unplanned sexual intercourse and be coerced into sex than their older counterparts. ${ }^{1,2}$ Hence, more than half become pregnant by the age of 18 or 19 , which is considered legal adulthood in many countries. ${ }^{1}$ We previously reported worse neonatal outcomes in younger adolescents as compared with older ones. ${ }^{12}$ Taking this into account, we further sought to analyze outcomes of teen mothers with severe preeclampsia and compare results according to their age. Contrary to our previous observations, the present study found that maternal and neonatal outcome in adolescents with severe preeclampsia was not influenced by teen's age. Furthermore, although neonatal outcome was similarly adverse in both groups; obstetrical outcome was fairly good, and there were no maternal deaths or severe complications. This is very important considering the difficulties of managing an overcrowded obstetrical setting as that found in our hospital; not to mention the heterogeneity of factors affecting individual maternal health, inadequate prenatal care and the complications related to the severity of preeclampsia.

The prevalence of preeclampsia may vary depending on the studied population. ${ }^{5,6}$ In the present study, severe preeclampsia accounted for $6 \%$ of all live births (excluding multiple pregnancies and other forms of hypertensive states), of which $13.5 \%$ were adolescents. Preeclampsia and hypertensive disorders are leading causes of maternal mortality. ${ }^{22,23}$ Putting into context the age of the mother (i.e., adolescents), the scenario is even more tragic. We have previously reported that a higher rate of women with severe preeclampsia come near term to deliver at Sotomayor

Table I Maternal sociodemographic and obstetrical outcome data of studied women $(n=2 / 3)$

\begin{tabular}{|c|c|c|c|}
\hline Parameters & $\begin{array}{l}\text { Adolescents } \\
\leq 16 \text { years, } \\
n=82\end{array}$ & $\begin{array}{l}\text { Adolescents } \\
\text { |7-19 years, } \\
n=13 \mid\end{array}$ & p-value* \\
\hline Maternal age (years) & $15.2 \pm 0.9$ & $18.2 \pm 0.8$ & $<0.00 I^{\mathrm{a}}$ \\
\hline Primigravid & $74(90.2)$ & I I 6 (88.5) & $0.69^{b}$ \\
\hline Systolic blood pressure upon admission $(\mathrm{mmHg})$ & $140[10.5]$ & $140[25.0]$ & $0.78^{c}$ \\
\hline Diastolic blood pressure upon admission $(\mathrm{mmHg})$ & $90[5.0]$ & $90[20.0]$ & $0.33^{c}$ \\
\hline Cohabiting with partner & $52(63.4)$ & $88(67.2)$ & $0.57^{\mathrm{b}}$ \\
\hline Rural residency & $32(39)$ & $48(36.7)$ & $0.72^{\mathrm{b}}$ \\
\hline Illicit drug abuse during pregnancy & $0(0)$ & $2(1.5)$ & $0.52^{\mathrm{d}}$ \\
\hline History of antenatal admission & $0(0)$ & $6(4.6)$ & $0.04^{d}$ \\
\hline Hemoglobin upon admission to labor ( $g / d L)$ & $11.4 \pm 1.5$ & $\mathrm{II} .4 \pm \mathrm{I} .4$ & $0.82^{\mathrm{a}}$ \\
\hline Prepartum hematocrit (\%) & $33.8 \pm 3.9$ & $34.1 \pm 3.4$ & $0.57^{a}$ \\
\hline Postpartum hematocrit (\%) & $31.7 \pm 3.2$ & $32.8 \pm 3.7$ & $0.16^{\mathrm{a}}$ \\
\hline Oligohydramnios & $4(4.9)$ & $3(2.3)$ & $0.30^{\mathrm{b}}$ \\
\hline Intrapartum meconium & $3(3.7)$ & $9(6.9)$ & $0.32^{\mathrm{b}}$ \\
\hline Premature rupture of membranes before admission & $3(3.7)$ & $5(3.8)$ & $0.95^{b}$ \\
\hline Abnormal fetal monitoring tracings & $5(6.1)$ & $7(5.3)$ & $0.8 \mathrm{I}^{\mathrm{b}}$ \\
\hline Delivery by cesarean section & $68(82.9)$ & I I7 (89.3) & $0.17^{\mathrm{b}}$ \\
\hline
\end{tabular}

Notes: Data are presented as mean \pm standard deviation, medians [interquartile ranges], frequencies or percentages $(\mathrm{n} \%)$. ${ }^{\mathrm{p}} \mathrm{p}$-value determined by Student's $t$-test ${ }^{\mathrm{a}}$, chisquare test ${ }^{\mathrm{b}}$, Mann-Whitney $U$-test ${ }^{\mathrm{c}}$, or Fisher's exact test ${ }^{\mathrm{d}}$. 
Table 2 Neonatal outcome of studied groups

\begin{tabular}{|c|c|c|c|}
\hline Parameters & $\begin{array}{l}\text { Adolescents } \leq 16 \\
\text { years, } n=82\end{array}$ & $\begin{array}{l}\text { Adolescents } 17-19 \\
\text { years, } n=131\end{array}$ & p-value \\
\hline Gestational age (weeks) & $37.4 \pm 2.2$ & $37.1 \pm 2.8$ & $0.55^{\mathrm{a}}$ \\
\hline Weight $(g)$ & $2,644[886.0]$ & $2,500[1,149]$ & $0.2 \mathrm{I}^{\mathrm{b}}$ \\
\hline Length $(\mathrm{cm})$ & $46.4 \pm 3.6$ & $45.6 \pm 4.3$ & $0.3 I^{a}$ \\
\hline Head circumference $(\mathrm{cm})$ & $32.6 \pm 2.1$ & $32.4 \pm 2.4$ & $0.8 I^{\mathrm{a}}$ \\
\hline Preterm & $19(23.2)$ & $41(31.3)$ & $0.23^{c}$ \\
\hline Small for gestational age & $26(31.7)$ & $47(35.9)$ & $0.53^{c}$ \\
\hline Low birth weight $(<2,500$ g) & $36(43.9)$ & $63(43.1)$ & $0.55^{c}$ \\
\hline $\begin{array}{l}\text { Small for gestational age }+ \text { intrauterine fetal growth } \\
\text { restriction }\end{array}$ & $3(3.7)$ & $5(3.8)$ & $0.95^{c}$ \\
\hline Apgar $<7$ at first minute & $19(23.2)$ & $30(22.9)$ & $0.96^{\mathrm{c}}$ \\
\hline Apgar $<7$ at fifth minute & $7(8.5)$ & $15(11.4)$ & $0.49^{c}$ \\
\hline Admissions to neonatal intensive care unit & $26(31.7)$ & $51(38.9)$ & $0.28^{c}$ \\
\hline Neonatal deaths & $0(0)$ & $4(3)$ & $0.30^{\mathrm{d}}$ \\
\hline Perinatal asphyxia & $5(6.1)$ & II (8.4) & $0.53^{c}$ \\
\hline Acute respiratory distress syndrome & $17(20.7)$ & $33(25.2)$ & $0.45^{c}$ \\
\hline Neonatal hyperbilirubinemia & $10(12.2)$ & $23(17.6)$ & $0.29 c$ \\
\hline
\end{tabular}

Notes: Data are presented as mean \pm standard deviation, medians [interquartile ranges], frequencies or percentages ( $n$, \%). $p$-value determined by Student's $t$-test ${ }^{\mathrm{a}}$, MannWhitney $U$-test ${ }^{b}$, chi-square test ${ }^{c}$, or Fisher's exact test ${ }^{d}$.

Hospital; ${ }^{24}$ this fact is attributed to inadequate prenatal care. ${ }^{25}$ Adequacy of prenatal care aims at identifying preeclampsia cases in their early stages in order to induce labor and obtain better maternal fetal outcomes (i.e., those with near-term mild preeclampsia). Induction of labor in women with severe preeclampsia requires a very strategical approach in order to reassure positive maternal and fetal outcomes. Previous studies have reported that more than a half of young women with preeclampsia deliver by cesarean section. ${ }^{6}$ Cesarean section rate is high in our hospital, in teens and those with preeclampsia. ${ }^{12,24}$ Same increased trend was found in the present sample of teens with severe preeclampsia, yet similar in both studied groups. We recognize that this as an issue, and attributed, at least in part, to the overcrowded delivery ward. Nevertheless, it is important to bear in mind that our institutional mission is to guarantee by all means life for both the mother and her child and that Sotomayor Hospital receives a high rate of referrals of women with severe obstetrical and/or maternal complications, and among these are severe preeclampsia cases with an unripe cervix, uncontrollable blood pressure and signs of neurological compromise, the main cause of cesarean section in the present series. Under these circumstances, delivery must be prompt through the abdominal route. Despite the fact that preeclampsia cases were severe with signs of organ compromise, there were no maternal deaths, as has been reported in other similar scenarios. ${ }^{26}$ In our case in particular, the reduction of cesarean section rates in cases of severe preeclampsia would require a comprehensive individualized approach, bearing in mind quality of intrapartum care, maternal and fetal safety, and the early identification and management of this complication. This approach is not easy, however, if one faces an overcrowded obstetrical flow. On the other hand, it is also very important to guarantee family planning to young mothers to prevent subsequent pregnancies, and therefore avoid short intergestational intervals with well-recognized consequences (i.e., preterm birth, repeated preeclampsia, IUGR and so on). ${ }^{1,27}$

Adverse neonatal outcomes have been reported in teen mothers. ${ }^{3,6,12}$ However, to the best of our knowledge, the present study is perhaps the first to report similar adverse neonatal outcome in teen mothers with severe preeclampsia in which maternal age did not seem to influence results.

As for the limitations of this study, one can mention its retrospective design, which limits the amount of obtained information. Hence, our results cannot totally be extrapolated to the entire Ecuadorian population. We did not include additional comparative study groups (age 20-30 and one without preeclampsia); this may also be seen as a potent limitation. Despite these limitations, the study has its strengths: a) data are obtained from a specific low-income population mainly coming from rural and marginal areas of the Ecuadorian coast, basically attended at Sotomayor Hospital, and b) our data add to the few or no reports found in the literature comparing outcomes in teens with severe preeclampsia in accordance to their age.

Teens are a vulnerable population and a public health concern. Antenatal and intrapartum care in our scenario requires 
urgent attention and improvement. The information provided by this research can serve as model to improve maternal health care in our country or other developing ones with similar settings. We propose a) improvement of adequacy of prenatal care;28 b) enhancement of reproductive health education to teens (boys and girls) and c) the promotion of the protection of girl's rights and eradication of intimate partner violence and the risk of undesired pregnancies. Socialization of women's rights and their roles in the society should be a worldwide priority, at the same level of males.

\section{Conclusion}

Pregnancy outcome in this adolescent population with severe preeclampsia was similarly adverse, independent of maternal age. There is a need for further research in this regard and to promote awareness of the problem to the general population.

\section{Author contributions}

F.R.P.-L. and P.C. designed the study. P.E.P.-P. and L.A.Q.A. collected clinical data. P.C. and L.H. performed statistical analysis. All authors contributed in the drafting of the manuscript and then critically revising the final version. All authors agree to be accountable for all aspects of the work.

\section{Disclosure}

The authors report no conflicts of interest in this work.

\section{References}

1. Perez-Lopez FR, Chedraui P, Kravitz AS, Salazar-Pousada D, Hidalgo L. Present problems and controversies concerning pregnant adolescents. Open Access J Contracept. 2011;2:85-94.

2. Salazar-Pousada D, Astudillo C, Gonzaga M, Hidalgo L, Perez-Lopez FR, Chedraui P. Intimate partner violence and psychoemotional disturbance among pregnant women admitted to hospital with prenatal complications. Int J Gynaecol Obstet. 2012;118(3):194-197.

3. Traisrisilp K, Jaiprom J, Luewan S, Tongsong T. Pregnancy outcomes among mothers aged 15 years or less. J Obstet Gynaecol Res. 2015; 41(11):1726-1731.

4. Zárate A, Saucedo R, Valencia J, Manuel L, Hernández M. Early disturbed placental ischemia and hypoxia creates immune alteration and vascular disorder causing preeclampsia. Arch Med Res. 2014;45(7):519-524.

5. Scholl TO, Hediger ML, Belsky DH. Prenatal care and maternal health during adolescent pregnancy: a review and meta-analysis. J Adolesc Health. 1994;15(6):444-456.

6. Kawakita T, Wilson K, Grantz KL, Landy HJ, Huang CC, Gomez-Lobo V. Adverse maternal and neonatal outcomes in adolescent pregnancy. J Pediatr Adolesc Gynecol. 2016;29(2):130-136.

7. Zhang J, Meikle S, Trumble A. Severe maternal morbidity associated with hypertensive disorders in pregnancy in the United States. Hypertens Pregnancy. 2003;22(2):203-212.

8. Cruz MO, Gao W, Hibbard JU. Obstetrical and perinatal outcomes among women with gestational hypertension, mild preeclampsia, and mild chronic hypertension. Am J Obstet Gynecol. 2011;205(3):260.e1-260.e9.
9. Abalos E, Cuesta C, Carroli G, et al; WHO Multicountry Survey on Maternal and Newborn Health Research Network. Pre-eclampsia, eclampsia and adverse maternal and perinatal outcomes: a secondary analysis of the World Health Organization Multicountry Survey on Maternal and Newborn Health. BJOG. 2014;121(Suppl 1):14-24.

10. Chang JJ, Strauss JF 3rd, Deshazo JP, Rigby FB, Chelmow DP, Macones GA. Reassessing the impact of smoking on preeclampsia/eclampsia: are there age and racial differences? PLoS One. 2014;9(10):e106446.

11. Savitz DA, Danilack VA, Engel SM, Elston B, Lipkind HS. Descriptive epidemiology of chronic hypertension, gestational hypertension, and preeclampsia in New York State, 1995-2004. Matern Child Health J. 2014;18(4):829-838.

12. Hidalgo LA, Chedraui PA, Chávez MJ. Obstetrical and neonatal outcome in young adolescents of low socio-economic status: a case control study. Arch Gynecol Obstet. 2005;271(3):207-211.

13. Kashanian M, Aghbali F, Mahali N. Evaluation of the diagnostic value of the first-trimester maternal serum high-sensitivity C-reactive protein level for prediction of pre-eclampsia. J Obstet Gynaecol Res. 2013;39(12):1549-1554.

14. O'Gorman N, Wright D, Syngelaki A, et al. Competing risks model in screening for preeclampsia by maternal factors and biomarkers at 11-13 weeks gestation. Am J Obstet Gynecol. 2016;214(1):103.e1-103.e12.

15. Salazar-Pousada D, Chedraui P, Villao A, Pérez-Roncero GR, Hidalgo L. Resultados maternos y perinatales en gestantes nulíparas con preeclampsia de aparición tardía: Estudio comparativo frente a gestantes sin preeclampsia [Maternal and perinatal outcomes in nulliparous gestations with late onset preeclampsia: comparative study with gestations without preeclampsia]. Enferm Clin 2014;24(6):345-350. Spanish.

16. Phoa KY, Chedraui P, Pérez-López FR, et al. Perinatal outcome in singleton pregnancies complicated with preeclampsia and eclampsia in Ecuador. J Obstet Gynaecol 2016;36(5):581-584.

17. Junta de Beneficencia de Guayaquil. Available from: www.juntadebeneficencia.org.ec. Accessed November 21, 2016.

18. El Índice de Precios al Consumidor (IPC) Canastas. Available from: http://www.ecuadorencifras.gob.ec/canasta/. Accessed November 21, 2016.

19. American College of Obstetricians and Gynecologists. Hypertension in pregnancy. Obstet Gynecol. 2013;122:1122-1131.

20. Ballard JL, Novak KK, Driver M. A simplified score for assessment of fetal maturation of newly born infants. J Pediatr. 1979;95(5 Pt 1):769-774.

21. Valero De Bernabe J, Soriano T, Albaladejo R, et al. Risk factors for low birth weight: a review. Eur J Obstet Gynecol Reprod Biol. 2004; 116(1):3-15.

22. Lo JO, Mission JF, Caughey AB. Hypertensive disease of pregnancy and maternal mortality. Curr Opin Obstet Gynecol. 2013;25(2):124-132.

23. Thornton C, Dahlen H, Korda A, Hennessy A. The incidence of preeclampsia and eclampsia and associated maternal mortality in Australia from population-linked datasets: 2000-2008. Am J Obstet Gynecol. 2013;208(6):476.e1-5.

24. Chedraui P, Lockwood CJ, Schatz F, et al. Increased plasma soluble fms-like tyrosine kinase 1 and endoglin levels in pregnancies complicated with preeclampsia. J Matern Fetal Neonatal Med. 2009;22(7): 565-570.

25. Paredes I, Hidalgo L, Chedraui P, Palma J, Eugenio J. Factors associated with inadequate prenatal care in Ecuadorian women. Int J Gynaecol Obstet. 2005;88(2):168-172.

26. Koum K, Hy S, Tiv S, et al. Characteristics of antepartum and intrapartum eclampsia in the National Maternal and Child Health Center in Cambodia. J Obstet Gynaecol Res. 2004;30(2):74-79.

27. Ventura W, Ventura-Laveriano J, Nazario-Redondo C. Perinatal outcomes associated with subsequent pregnancy among adolescent mothers in Peru. Int J Gynaecol Obstet. 2012;117(1):56-60.

28. Goldenberg RL, Jones B, Griffin JB, et al. Reducing maternal mortality from preeclampsia and eclampsia in low-resource countries - what should work? Acta Obstet Gynecol Scand. 2015;94(2):148-155. 


\section{Publish your work in this journal}

Adolescent Health, Medicine and Therapeutics is an international, peer-reviewed, open access journal focusing on health, pathology, and treatment issues specific to the adolescent age group. All aspects of health maintenance, preventative measures and disease treatment interventions are addressed within the journal and practitioners from all disciplines are invited to submit their work as well as healthcare researchers and patient support groups. This journal is included in PubMed. The manuscript management system is completely online and includes a very quick and fair peer-review system. Visit http://www.dovepress.com/testimonials. php to read real quotes from published authors.

Submit your manuscript here: http://www.dovepress.com/adolescent-health-medicine-and-therapeutics-journal 